\title{
LEITURA MULTIMODAL DE INFOG RÁFICO: UM ESTUDO EM AULAS DE LÍNGUA PORTUGUESA NO ENSINO MÉDIO
}

\author{
MULTIMODAL INFOGRAPHIC READING: A STUDY IN \\ PORTUGUESE LANGUAGE CLASSES IN HIGH SCHOOL
}

\author{
Naziozênio Antonio Lacerda" \\ Agnaldo Rodrigues Vieira**
}

\begin{abstract}
Resumo: O objetivo desta pesquisa é analisar um estudo sobre a leitura multimodal de infográfico em aula de língua portuguesa no ensino médio. A pesquisa fundamentase teoricamente nos estudos de Kress e Van Leeuwen (2001; 2006[1996]), Dionísio e Vasconcelos (2013) e Vieira (2015) sobre multimodalidade; de Paes de Barros (2009), a respeito de estratégias cognitivas de leitura; e de Coscarelli (2002), Furst (2010) e Paiva (2016), sobre leitura de infográfico. Na metodologia, adota-se uma abordagem qualitativa de pesquisa e usa-se o método da pesquisa-ação. Como instrumento de pesquisa, aplica-se um roteiro de entrevista estruturada com 15 (quinze) alunos do $3^{\circ}$ ano do ensino médio de uma escola pública estadual, sediada em Teresina, Piauí. Os resultados mostram que o aspecto que chamou mais a atenção dos alunos na leitura multimodal do infográfico foram as imagens (80\%) e que a estratégia cognitiva mais utilizada pelos alunos consistiu na leitura das informações visuais (86,6\%).
\end{abstract}

Palavras-chave: Leitura multimodal; Infográfico; Língua portuguesa.

Aвstract: The objective of this research is to analyze a study on the multimodal reading of infographic in a Portuguese language class in high school. The research is theoretically based on the studies of Kress and Van Leeuwen (2001; 2006 [1996]), Dionísio and Vasconcelos (2013) and Vieira (2015) on multimodality; Paes de Barros (2009), regarding cognitive reading strategies; and Coscarelli (2002), Furst (2010) and Paiva (2016), on reading infographic. In the methodology, a qualitative approach is adopted and the action research method is used. As a research tool, a structured

\footnotetext{
"Doutor em Estudos Linguísticos (Linguística Aplicada) pela Universidade Federal de Minas Gerais (UFMG) e professor da graduação e do Programa de Pós-Graduação em Letras (PPGEL) da Universidade Federal do Piauí (UFPI). E-mail: zenolacerda@gmail.com.

" Graduado em Letras-Língua Portuguesa e Literatura de Língua Portuguesa pela Universidade Federal do Piauí (UFPI). E-mail: agnaldorodrigues2r@gmail.com.
} 
interview script is applied with 15 (fifteen) students of the 3 rd year of high school in a state public school, based in Teresina, Piauí. The results show that the aspect that attracted most the students' attention in the multimodal reading of the infographic was the images (80\%) and that the cognitive strategy most used by the students consisted in reading the visual information (86.6\%).

KeYwords: Multimodal reading; Infographic; Portuguese language.

\section{INTRODUÇão}

A evolução das tecnologias digitais da informação e comunicação (TDIC) tem provocado novas demandas nas práticas sociais da leitura e da escrita de gêneros textuais multimodais, constituídos por múltiplas linguagens que levam a multissemioses.

O infográfico constitui um exemplo de gênero textual multimodal composto por diferentes modos semióticos, principalmente o visual e o verbal, funcionando de maneira articulada para a produção de sentidos.

As imagens que compõem o gênero textual infográfico parecem combinar-se mais adequadamente com as vivências dos alunos. Por ser predominantemente visual, o infográfico atende às exigências dos leitores contemporâneos, que preferem fazer uma leitura rápida por meio de imagens, cores e gráficos, combinados com a informação verbal.

Dessa forma, a leitura do infográfico é uma prática que os alunos sentem a necessidade de desenvolver no ambiente escolar em razão desse gênero digital circular em diferentes suportes midiáticos que fazem parte do universo social e cultural dos discentes.

Justificamos que a realização desta pesquisa sobre o infográfico em sala de aula é importante porque esse gênero textual está presente na sociedade, no dia a dia dos alunos, mas não tem sido trabalhado com muita frequência em aulas de língua portuguesa e os alunos sentem dificuldades em fazer uma leitura multimodal.

Diante desse problema real da educação básica que identificamos em sala de aula do ensino médio, levantamos as seguintes questões: Quais aspectos chamam mais a atenção dos alunos na leitura do infográfico? Que estratégias cognitivas os alunos usam na leitura multimodal do infográfico?

Para responder a essas perguntas, a nossa pesquisa tem como objetivo geral analisar um estudo sobre a leitura multimodal do infográfico em aula de língua portuguesa no ensino médio. E apresenta como objetivos específicos: discutir a leitura multimodal de infográfico; identificar os aspectos que mais chamam a atenção dos alunos na leitura de infográfico; verificar quais as estratégias cognitivas de leitura usadas pelos alunos na leitura multimodal de infográfico; inferir se os alunos estabelecem relações entre a leitura da parte visual e da 
parte verbal do infográfico para produção de sentidos; e refletir sobre a leitura multimodal do infográfico em aula de língua portuguesa no ensino médio.

A nossa pesquisa segue a perspectiva teórica da multimodalidade, considerando o infográfico um gênero multimodal, e usa estratégias cognitivas de leitura de textos multimodais. Para abordagem da temática, buscamos fundamentação nos estudos de Kress e Van Leeuwen (2001; 2006[1996]), Dionísio e Vasconcelos (2013) e Vieira (2015), sobre multimodalidade; de Paes de Barros (2009), a respeito de estratégias cognitivas de leitura em texto multimodal; e de Coscarelli (2002), Furst (2010), Lima (2015), Paiva (2016) e Roza e Menezes (2019), no tocante à leitura do gênero textual infográfico, entre outros.

Estruturamos o nosso artigo em 4 (quatro) seções. Na primeira seção, abordamos a leitura e a multimodalidade. Na segunda seção, discutimos a leitura multimodal de infográfico. $\mathrm{Na}$ terceira seção, explicitamos a metodologia da pesquisa, descrevendo as etapas do estudo em aula de língua portuguesa no ensino médio. Na quarta seção, analisamos e discutimos os resultados da pesquisa sobre a leitura de infográfico em sala de aula. E depois acrescentamos as nossas considerações finais a respeito da realização do estudo e dos resultados obtidos na investigação.

\section{LEITURA E MULTIMODALIDADE}

Nos últimos tempos, devido ao crescente avanço das tecnologias, a sociedade vem passando por uma verdadeira revolução comunicacional e as relações que os sujeitos estabelecem com a informação são cada vez mais caracterizadas pela interação de diferentes modos de linguagem. Assim, na contemporaneidade, vemos surgir um número cada vez maior de textos que se utilizam de várias linguagens ao mesmo tempo. Esse tipo de texto, bastante recorrente nas práticas sociais pós-modernas, é chamado de texto multimodal (FERRAZ, 2008).

A noção de multimodalidade surge no seio da teoria semiótica, mais especificamente da semiótica social, cujos estudos começam a ser divulgados por Kress e Van Leeuwen (2006[1996]). Em estudos posteriores, os mesmos autores destacam que os modos semióticos se unem em uma produção discursiva ou textual. Os modos semióticos são o visual, verbal, gestual/espacial, sonoro e muitos outros expressos em diferentes linguagens. Por exemplo: imagem e palavra se completam e interagem para significar mais. Assim, a multimodalidade passa a ser entendida como a combinação de diferentes modos semióticos em uma produção textual (KRESS; VAN LEEUWEN, 2001).

Seguindo essa linha de pensamento, todas as formas de comunicação são multimodais porque envolvem diferentes modos semióticos, constituídos por múltiplas linguagens e organizados para favorecer a significação. 
Dionísio e Vasconcelos (2013, p. 19) destacam que "a sociedade na qual vivemos se constitui como um grande ambiente multimodal, no qual palavras, imagens, sons, cores, músicas, aromas, movimentos variados, texturas, formas diversas se combinam e estruturam um grande mosaico multissemiótico".

Essa afirmativa traz uma contribuição significativa para entendermos a presença da multimodalidade na sociedade contemporânea, preparando-nos para nos comunicar em um mundo com diferentes linguagens e ajudando-nos a compreender as relações multissemióticas e os significados de nossas ações com o mundo.

Atualmente, vemos surgir a todo instante textos envoltos por multissemioses como: sons, texto verbal, imagens, cores variadas, etc. A este respeito, Aquino (2014, p. 1337) aponta que:

[...] considerando as múltiplas linguagens envolvidas na produção do texto, lemos muito mais do que o texto verbal. A leitura de imagens, cores, etc. faz-se necessária para compreendermos os mais diversos sentidos evidenciados das e nas práticas sociais de uso da escrita.

Com base na afirmativa do autor, percebemos que o surgimento de textos multimodais, com diferentes multissemioses proporcionadas pelas imagens, cores, texto verbal e outros modos semióticos, acaba nos envolvendo nas atividades de leitura e nas práticas multiletradas.

Oliveira (2013. p. 1) enfatiza que "nas práticas sociais pós-modernas, os cidadãos estão cada vez mais sendo expostos à leitura de textos que misturam escrita, layout, imagens, som e objetos 3D". Desse modo, um leitor apto para o mundo moderno não é aquele que apenas decodifica o verbal, mas sim o que processa e confere sentido às diferentes semioses envolvidas no processo comunicativo.

Na visão de Dionisio, Vasconcelos e Souza (2014, p. 41), “as nossas práticas de leitura e de escrita sinalizam nossa forma de viver as linguagens, de conviver com as multissemioses da nossa sociedade multiletrada".

Compreendemos que esse processo de construção multimodal é pertinente para interpretarmos as mudanças comunicacionais pelas quais a sociedade moderna vem passando, principalmente, no que tange às novas exigências nas práticas de leitura e escrita que têm levado à necessidade de novos tipos de letramentos.

O aspecto visível do texto multimodal ao primeiro olhar do leitor é a saliência (KRESS; VAN LEEUWEN, 2006[1996]). Os elementos utilizados na saliência "têm o claro intuito de atrair a atenção do espectador para diferentes aspectos da composição, como a localização em primeiro ou segundo plano; o tamanho relativo da imagem; o contraste em cores; as diferenças de nitidez, entre outros aspectos" (VIEIRA, 2015, p. 68).

Pelo que vimos, a sociedade globalizada está exigindo cada vez mais dos cidadãos uma competência comunicativa multimodal. Nessa realidade em que estamos inseridos, o texto 
multimodal, em razão de sua composição e arranjo não padronizado, exige do leitor atual uma maneira diferenciada de ler em se comparando com o leitor tradicional:

A leitura do texto multimodal requer o desenvolvimento das capacidades de linguagem com diferentes semioses em seu conjunto, de modo integrativo e interativo. A inaptidão para ler, mesmo que seja apenas um dos signos das várias semioses que o constitui, implicará a incompletude de sua compreensão leitora. (ROZA; MENEZES, 2019, p. 132)

Ancorados nessa citação, entendemos que, na leitura de um texto multimodal, o leitor deve ler os signos de cada semiose, bem como estabelecer relações entre eles e os outros signos das demais semioses, em um processo de interconexão dos diferentes modos, construindo ressignificações pela mescla de múltiplas linguagens, a fim de atingir a compreensão leitora e potencializar a produção de sentidos.

E, de acordo com a Base Nacional Comum Curricular (BRASIL, 2018), podemos dizer que a leitura de textos multissemióticos em sala de aula de língua portuguesa contribui para o aluno explorar e compreender os modos como as diferentes linguagens se combinam.

Nesta seção, sob um prisma abrangente, no âmbito da relação entre leitura e multimodalidade, abordamos a leitura do texto multimodal em geral. Na seção seguinte, vamos discutir especificamente a leitura de um gênero textual multimodal: o infográfico, objeto de nossa investigação em sala de aula.

\section{A leitura multimodal de infográficos}

Com o desenvolvimento das tecnologias digitais da informação e comunicação (TDIC), o texto deixou de ser apenas uma unidade formal de estrutura exclusivamente linear, construída somente pela linguagem verbal, e adquiriu uma estrutura mais fragmentária, abrangendo imagens, sons, movimentos, ícones e blocos de informação textuais. Com isso, o texto passou a ser multimídia e ganhou um caráter multimodal.

Essas modificações na organização do texto trouxeram consequentemente alterações na leitura dos textos multimodais em geral, inclusive de infográficos. Coscarelli (2002, p. 75) menciona que existem várias conexões durante a leitura dos infográficos, "podendo o leitor começar sua interpretação a partir da linguagem não verbal ou da linguagem verbal, não tendo uma estrutura rígida a ser seguida”.

Ainda a esse respeito, Braga (2009) afirma que o infográfico possui uma ampla capacidade de chamar a atenção do leitor, de entretê-lo por meios de imagens e de outros elementos pictográficos. Observamos com isso que o leitor ganha mais autonomia e participa ativamente da leitura, exercendo a sua liberdade de iniciar a leitura voltada ao elemento que mais lhe chamar a atenção. 
Na visão de Furst (2010), com essas mudanças observadas, cada leitor construirá a sequência de leitura que lhe assentir, podendo iniciar a leitura do trecho que mais lhe chamar atenção. A autora ainda acrescenta que

as novas tecnologias trouxeram consigo novos tipos de textos: a multimídia, o hipertexto e a hipermídia. Os infográficos se enquadram exatamente nesse último tipo. Portanto, enquanto uma hipermídia, podemos caracterizar a leitura de um infográfico como uma leitura não linear que pode ser percorrida de inúmeras maneiras, a critério do leitor, além de incluir outros meios não verbais, como desenho, animação ou fotografia, som, movimento, iluminação (FURST, 2010, p. 80).

Com base na afirmativa dessa citação, podemos entender que a leitura multimodal de infográficos é diferente da leitura de um texto linear (que segue a organização previamente definida pelo autor), caracterizando-se como uma leitura hipertextual de natureza rizomática. Dessa forma, na leitura do infográfico, o leitor terá que lidar com vários planos ao mesmo tempo, decidir de que parte iniciará, fazer inferências o tempo todo e associar blocos de informação com imagens, estabelecendo uma relação simultânea entre o verbal e o não verbal para a continuidade temática e textual e produção de sentidos.

Ao estudar infográficos no meio jornalístico, Lima (2015) argumenta que a leitura desse tipo de texto não segue regras tão bem estabelecidas quanto às dos textos que empregam apenas linguagem verbal. Segundo o autor, a leitura do gênero infográfico aponta para características de ordem não linear de leitura, "oferecendo mais liberdade para o leitor ao lhe possibilitar uma estratégia de leitura própria, ou seja, o leitor passa a poder escolher a forma como irá ler a imagem ou texto" (LIMA, 2015, p. 116).

A partir dessa argumentação do autor citado, podemos compreender que a leitura de infográficos segue uma lógica diferenciada da maioria dos textos essencialmente verbais, pois, na leitura desse gênero, conseguimos escolher diferentes caminhos e a informação ainda será lógica e coerente. Assim, seguindo essa perspectiva, grande parte dos infográficos pode ser lido: de cima para baixo, de baixo para cima, da esquerda para a direita ou vice-versa, e a leitura ainda fará sentido, diferentemente da maioria dos textos verbais que muitas vezes carecem de uma leitura linear e efetiva de todas as partes para se conseguir o entendimento desejado.

Ainda no que concerne à leitura de infográficos, Paiva (2016, p. 45) enfatiza que

o leitor precisa relacionar as informações presentes nos diferentes modos semióticos para a produção de coerência e, consequentemente, para a compreensão, porque os elementos não verbais de um infográfico são sistematicamente processados pelo leitor, assim como acontece no texto verbal. O infográfico, como qualquer outro texto, precisa ser textualizado. 
Nesse ponto, concordamos com a concepção de Paiva, pois, acima de tudo, o infográfico é um texto, e este precisa ser interpretado pelo seu leitor. Assim, para uma leitura hábil do gênero, fica evidente a necessidade de associar as informações envolvidas nos mais variados elementos que compõem o infográfico. No entanto, esse processo de leitura de textos verbo-imagéticos aponta para a necessidade de competências e habilidades diferenciadas das práticas tradicionais.

A esse respeito, Paiva (2016, p. 47) destaca que "ter competência para ler infográficos é ser capaz de realizar essa leitura utilizando um conjunto de habilidades" que também é importante para a leitura de outros textos visuais.

Para explicar esse processo de leitura de infográficos, envolvendo diferentes aptidões, o autor citado propõe que essas habilidades sejam analisadas em dois níveis. O primeiro nível (mais amplo) requer "habilidades gerais", necessárias para a leitura de infográficos e dos demais textos visuais: envolve identificar, comparar e contrapor os dados dos mais diversificados modos semióticos. Já o segundo nível (mais específico) envolve "habilidades específicas" e conhecimentos mais direcionados para o gênero, como: clicar, arrastar ou ampliar com o mouse para se chegar a uma determinada informação ou estabelecer um encadeamento entre elas.

Dionísio (2011, p. 138), corroborando esse ponto de vista, aponta que "na atualidade, uma pessoa letrada deve ser alguém capaz de atribuir sentidos a mensagens oriundas de múltiplas fontes de linguagem". Assim, vemos que atualmente incorporar práticas de leitura envolvendo textos multimodais se tornou um fato cada vez mais comum e requisitado tanto pelo campo educacional quanto pela sociedade na qual vivemos. Dessa maneira, estamos de acordo com a posição de Dionísio quando afirma que ser letrado na atualidade implica muito mais do que simplesmente fazer juízo do verbal, exprime conferir significados a essa gama de modos semióticos que compõem a nossa sociedade.

É nesse contexto que compreendemos a leitura multimodal de infográficos como um conjunto de atribuições de sentidos, que se fazem por meio das relações dos diferentes modos de linguagens. Assim, enxergamos essa leitura como um processo complexo, que exige do leitor o ato de estabelecer relações entre elementos verbais e de outros modos semióticos.

[...] em textos como os infográficos, existem diversas informações em diferentes modos de apresentação como o verbal e o imagético, por exemplo, sendo preciso que o leitor saiba relacioná-las: ora relacionar informações imagéticas entre si, ora relacioná-las a informações de outros modos como o verbal. Ao mesmo tempo em que as relaciona, o leitor precisa avaliar se as articulações estabelecidas são corretas, pertinentes e adequadas a seu propósito (PAIVA, 2016, p. 49).

Como vemos, a leitura multimodal de infográficos abrange uma sintaxe de relacionamento e avaliação entre múltiplos modos semióticos que, a princípio, envolve habilidades 
comuns a outras modalidades, como, por exemplo, verbais e visuais. No entanto, em nosso entendimento, a leitura de infográficos envolve uma dinâmica diferenciada, na qual o leitor precisa levar em conta o layout desse gênero textual e saber relacionar/avaliar as informações visuais entre si e com outros modos como o verbal, bem como entre todos os modos semióticos presentes, a fim de estabelecer uma coerência para produção de sentidos.

Dessa forma, em se tratando do infográfico, a escola pode trabalhar estratégias de leitura que levem em conta cada modo e passem a englobar a relação entre os diferentes modos semióticos, como as estratégias propostas no esquema de leitura adotado por Paes de Barros (2009) e explicitado na metodologia desta pesquisa.

\section{Metodologia da PESQUisa}

Nesta seção, explicitamos a metodologia da pesquisa, fazendo uma caracterização do tipo de abordagem, método e contexto de investigação, e descrevendo o estudo da leitura multimodal de infográfico realizada em aulas de língua portuguesa no $3^{\circ}$ ano do ensino médio em uma escola pública.

\section{CARACTERIZAÇÃo DA PESQUISA}

No que concerne ao tipo de abordagem, optamos por uma pesquisa qualitativa para investigar a leitura multimodal do infográfico nas aulas de língua portuguesa no $3^{\circ}$ ano do ensino médio, visto que esse tipo de investigação nos permite uma análise mais aprofundada e detalhada sobre o que desejamos pesquisar. Todavia, Neves (1996) argumenta que o método de abordagem qualitativa não exclui o quantitativo e vice-versa. Por isso, complementamos a abordagem qualitativa com a abordagem quantitativa para mensurar os dados obtidos.

Adotamos o método da pesquisa-ação, que tem base empírica e é concebida e realizada de forma associada "com uma ação ou com a resolução de um problema coletivo e no qual os pesquisadores e os participantes representativos da situação ou do problema estão envolvidos de modo cooperativo ou participativo" (THIOLLENT, 2005, p. 16).

Realizamos a pesquisa em uma escola pública da rede estadual de educação, situada em Teresina, Piauí. A instituição possui dez salas de aulas climatizadas, laboratório de informática, biblioteca, quadra poliesportiva e refeitório. Em suma, a escola dispõe de uma boa estrutura física, e é limpa, iluminada e organizada. Atualmente atende a 475 alunos, distribuídos entre o $1^{\circ}$, o $2^{\circ}$ e $03^{\circ}$ anos do ensino médio. Escolhemos essa escola para a investigação porque o segundo autor desta pesquisa participava do Programa de Residência Pedagógica (UFPI/ CAPES) na referida instituição. Os participantes da pesquisa são 26 alunos de uma turma do 
$3^{\circ}$ ano do ensino médio, do turno da tarde. Como instrumento para a geração de dados da pesquisa, utilizamos um roteiro de entrevista semiestruturada junto aos alunos.

\section{DESCRIÇÃO DA EXPERIÊNCIA DO ESTUDO SOBRE A LEITURA DE INFOGRÁFICO}

Vivenciamos o estudo da leitura de infográfico em sala de aula com alunos do $3^{\mathrm{a}}$ ano do ensino médio em 4 (quatro) momentos que se constituíram em etapas da nossa pesquisa-ação (envolvendo diagnóstico, pesquisa, ação e reflexão): levantamento do perfil da turma e do conhecimento dos alunos sobre o gênero infográfico (diagnóstico), aula expositiva sobre o gênero infográfico em sala de aula (ação), leitura de um infográfico em sala de aula pelos alunos (pesquisa e ação) e aplicação de roteiro de entrevista semiestruturada para geração de dados (pesquisa e reflexão), as quais passamos a descrever de forma sucinta.

Etapa 1- Diagnóstico: Levantamento do PeRfil da turma e do Conhecimento dos alunos SOBRE O GÊNERO INFOGRÁFICO

No levantamento do perfil da turma, constatamos que, do total de 26 alunos, 16 alunos são do gênero feminino e 10 do gênero masculino, têm idade entre 16 e 18 anos e moram em diversos bairros das cidades de Teresina e de Altos, no Piauí.

Quanto ao diagnóstico do conhecimento da turma, procuramos saber se os alunos já conheciam o gênero textual infográfico. Verificamos que $80,8 \%$ (oitenta vírgula oito por cento) dos alunos informaram conhecer infográficos por meio de revistas, jornais, livro didático, redes sociais, televisão, propagandas, simulados e provas, mas não tinham a prática de leitura de infográfico em aulas de língua portuguesa. De outro modo, 19,2\% (dezenove vírgula dois por cento) disseram não conhecer esse gênero textual.

\section{ETAPA 2 - AÇÃo: Aula EXPositiva SObRe o GÊNERO INFográfico EM SALA DE AULA}

Com base no resultado do diagnóstico do conhecimento dos alunos, planejamos e ministramos uma aula expositiva sobre o gênero textual infográfico, com duração aproximada de 50 (cinquenta) minutos, utilizando-nos de recursos didáticos como o data show para projeção de infográfico em uma tela, com a finalidade de inteirar os alunos sobre a temática abordada.

Apresentamos conceitos de infográfico, suas principais aplicações, suportes e funcionalidades verbais e visuais. Tratamos também de princípios do design que regem a estrutura diversificada dos infográficos, como: cor, simetria, equilíbrio, contraste, direção, composição, profundidade, entre outros elementos. Por sua vez, os alunos procuraram discutir sobre a importância do infográfico na contemporaneidade. 


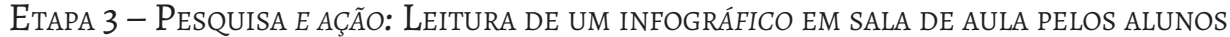

Selecionamos previamente um infográfico para a leitura dos alunos, publicado pela revista Superinteressante (2013), apresentado na próxima seção deste artigo. Justificamos que a escolha dessa revista levou em conta os critérios por se tratar de uma publicação de grande tiragem, com circulação nacional, dirigida ao público jovem e que se destaca por publicar infográficos sobre temas de interesse jornalístico, científico e social.

Durante a leitura, os alunos puderam perceber as diferentes informações que envolvem o infográfico, relação entre o verbal e o não verbal, diferença de leitura do infográfico dos textos convencionais e nível de atratividade das informações, entre outros aspectos.

Etapa 4 - Pesquisa e reflexão: Aplicação de roteiro de entrevista estruturada para GERAÇÃO DE DADOS

Como instrumento de pesquisa, utilizamos um roteiro de entrevista estruturada, com duas perguntas básicas sobre a leitura multimodal do infográfico, realizada na etapa 3 desta experiência em sala de aula, para uma amostra de 15 (quinze) alunos que afirmaram ter tempo e disponibilidade, bem como aceitaram participar voluntariamente da pesquisa. Todos os participantes integrantes da amostra foram orientados quanto à realização da pesquisa e assinaram o termo de consentimento livre e esclarecido.

Nesta etapa da pesquisa, tomamos como embasamento teórico, com as adaptações necessárias, o esquema de leitura de textos multimodais adotado por Paes de Barros (2009, p. 166), que alia materialidade visual à escrita:

1. Seleção e verificação das informações verbais (ativação das capacidades de compreensão e apreciação da leitura dos textos verbais).

2. Organização das informações da sintaxe visual (observação dos elementos visuais de modo a selecionar e organizar as informações relevantes à construção da significação).

3. Integração das informações verbais e visuais (capacidade de observar e conjugar as informações da materialidade verbal à visual, relacionando-as na construção de sentidos).

4. Percepção do todo unificado de sentido que se compõe através da integração dos materiais verbais e não verbais (ativação de diversas capacidades linguístico-discursivas e de leitura aliadas à organização e observação das informações, através das quais o leitor constrói um todo de significação).

Os dados gerados pelas respostas dos participantes da pesquisa no roteiro de entrevista estruturada são analisados e discutidos na próxima seção deste artigo para uma reflexão da experiência em aula de língua portuguesa. 


\section{ANÁLISE E discusSÃo doS RESULtAdos}

Nesta seção, efetuamos a análise e discutimos os resultados obtidos por meio de um roteiro de entrevista estruturada aplicado durante o estudo da leitura multimodal de um infográfico em aulas de língua portuguesa com alunos do $3^{\circ}$ do ensino médio.

\section{INFOGRÁFICO SELECIONADO PARA LEITURA MULTIMODAL EM SALA DE AULA}

$\mathrm{Na}$ etapa 3 de nossa experiência em sala de aula, conforme descrevemos na seção anterior, selecionamos or (um) infográfico para leitura multimodal pelos alunos de uma escola pública estadual em uma aula de língua portuguesa para uma turma do $3^{\circ}$ ano do ensino médio.

Ressaltamos que a escolha do infográfico selecionado teve como critério o objetivo de abordar um tema relevante para o contexto social dos alunos. Por isso, selecionamos o infográfico 'Prevenir a seca' (Fig. 1), publicado pela revista Superinteressante (2013).

Figura 1 - Infográfico 'Prevenir a seca'

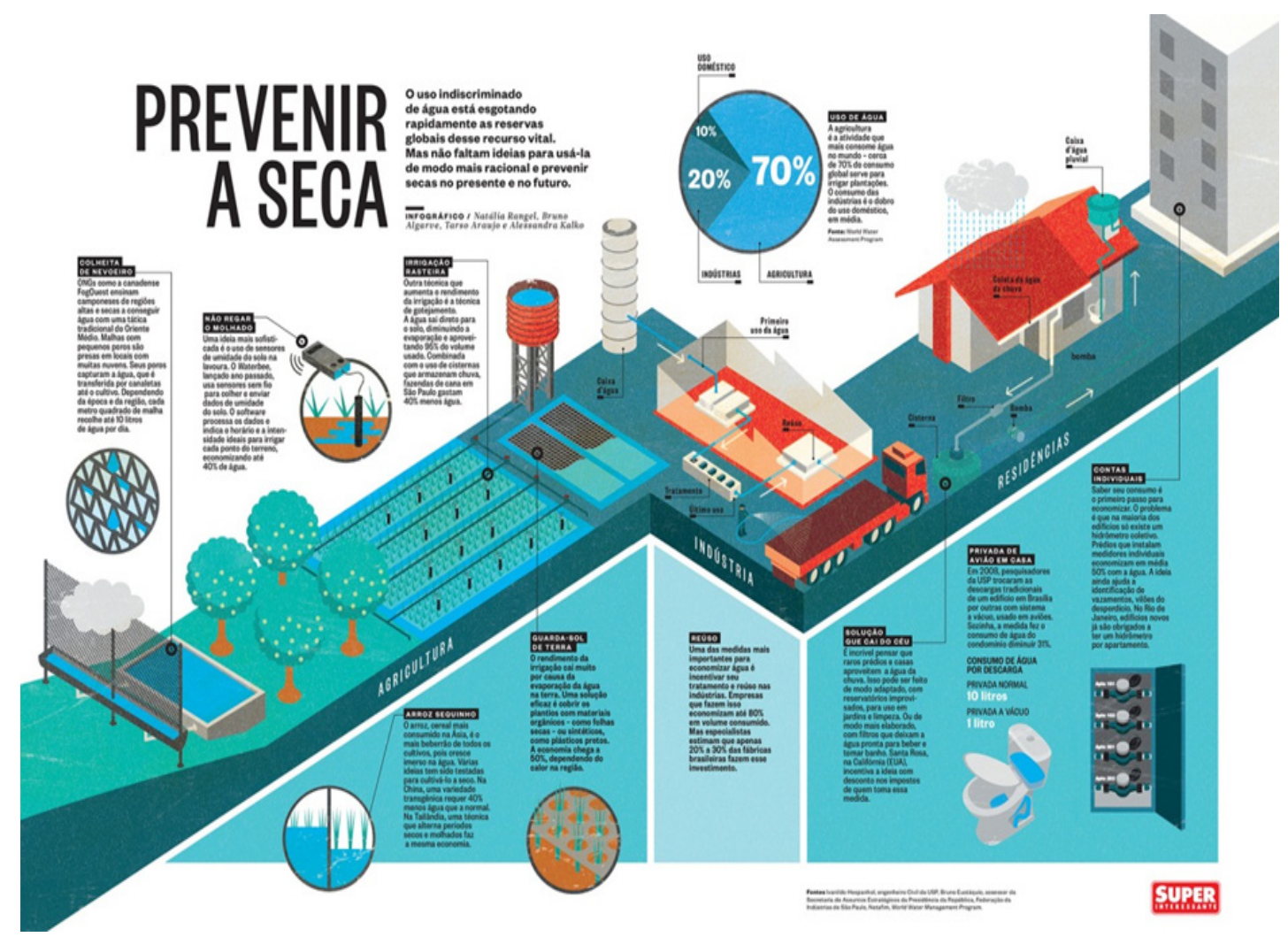

Fonte: Superinteressante (Edição 322, ago. 2013), disponível em http://planetasustentavel.abril.com.br/pops/ prevenir-a-seca-infografico-super-agosto.shtml 
Em nosso entendimento, o infográfico da Figura 1 é conceitual analítico, traz informações sobre o esgotamento das reservas globais de água e mostra alternativas para o uso racional desse recurso vital, cuja ideia serve para denominar o título: Prevenir a seca. A arte da elaboração do infográfico apresenta o percentual do consumo de água de acordo com o segmento - agricultura, indústria e uso doméstico.

A leitura multimodal do infográfico pode contribuir para a compreensão das informações e a produção de sentidos sobre as relações entre a sociedade e o meio ambiente, levando-nos a uma reflexão sobre o problema da escassez de água que poderá atingir as gerações do presente e do futuro em todo o planeta.

\section{ANÁlise E DISCUSSÃo DOS RESUlTAdos DA LEITURA MULTIMODAL DE INFOGRÁFICO}

Nesta subseção, analisamos e discutimos os dados gerados por meio de um roteiro de entrevista estruturada com uma amostra de 15 (quinze) alunos de uma escola pública estadual, participantes da pesquisa sobre o estudo da leitura multimodal de um infográfico em aulas de língua portuguesa para uma turma do $3^{\circ}$ ano do ensino médio, contribuindo para uma intensificação da perspectiva analítica e crítica de textos multissemióticos (BRASIL, 2018).

Para preservar a identidade dos participantes entrevistados, omitimos intencionalmente os seus nomes reais e os denominamos por um sistema alfanumérico, formado pela letra "A" (referente a aluno) seguida de uma numeração sequencial em algarismo arábico para identificação. Dessa forma, os alunos colaboradores da pesquisa são denominados de "A1 a A11".

Para geração dos dados, elaboramos um roteiro de entrevista estruturada com duas perguntas abertas, sem respostas para assinalar, a respeito da leitura do infográfico em aula de língua portuguesa no ensino médio.

A primeira pergunta formulada aos alunos entrevistados foi a seguinte: Que aspectos mais lhe chamaram a atenção na leitura do infográfico? Esta pergunta permitia múltiplas respostas, podendo o entrevistado responder livremente mais de um aspecto ao mesmo tempo, sem indicação de opções de respostas pelos pesquisadores. Sendo assim, cada aspecto respondido pode atingir o percentual de até cem por cento independentemente dos demais aspectos citados, podendo a soma dos percentuais ser superior a cem por cento. Depois categorizamos as respostas dos alunos e apresentamos o resultado no Gráfico 1. 
Gráfico 1- Aspectos que mais chamaram a atenção dos alunos na leitura do infográfico

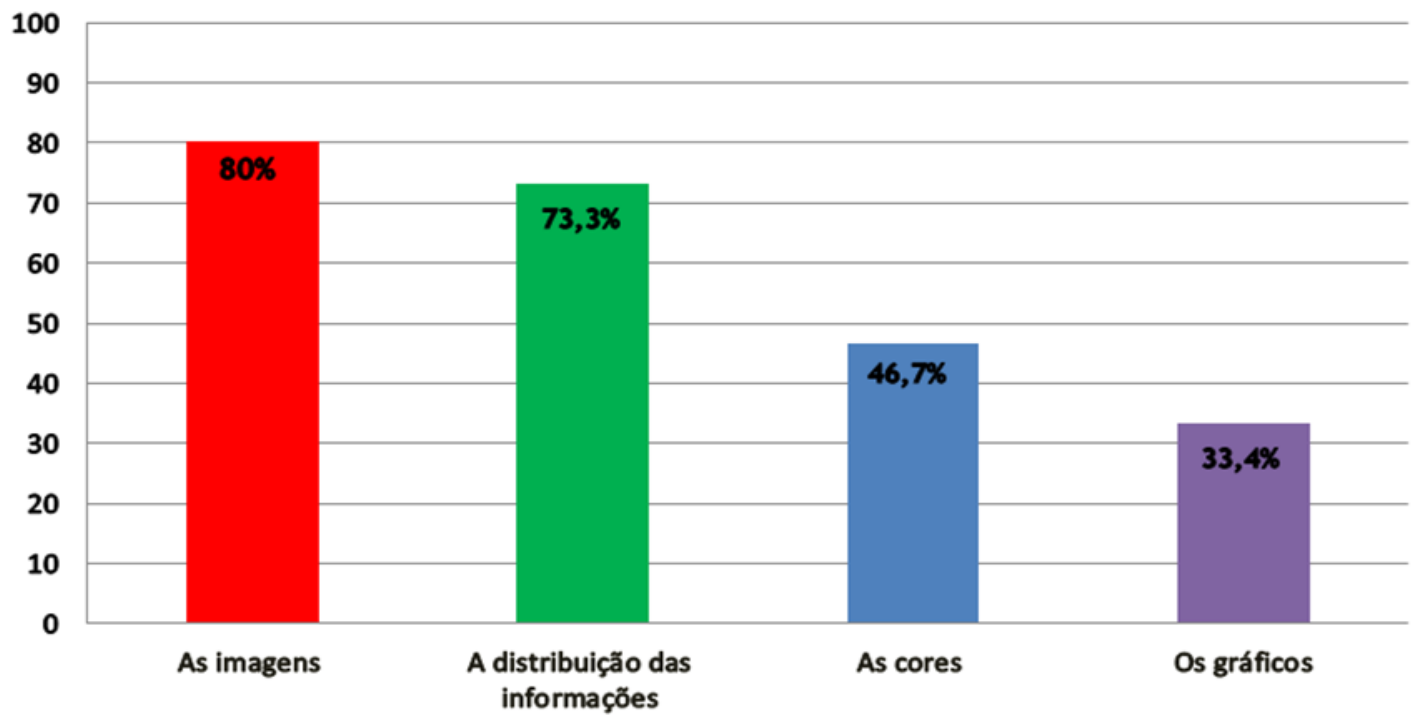

Fonte: Elaboração própria.

A dinamicidade do infográfico, com palavras e imagens, chama a atenção do leitor e pode despertar o interesse dos educandos. As respostas dos alunos foram agrupadas em quatro categorias, conforme os aspectos que mais chamaram a atenção na leitura do infográfico pelos entrevistados: as imagens (80\%), a distribuição das informações $(73,3 \%)$, as cores $(46,7 \%)$ e os gráficos (33,4\%).

A análise da primeira categoria nos mostra que, para $80 \%$ (oitenta por cento) dos alunos entrevistados, as imagens constituem o componente que mais chamou a atenção na leitura do infográfico, alcançando o maior percentual.

Selecionamos quatro respostas dadas pelos alunos A2, A5, A9 e A12, transcritas a seguir, que confirmam as imagens como o aspecto que mais chama a atenção na leitura do infográfico:

"As imagens, o fundo para o texto, isso que chama mais atenção" (A2).

"As imagens, onde as pessoas conseguem aprender mais" (A5).

"As imagens, e o fato da leitura não ter uma sequência obrigatória" (A9).

"As imagens" (A12).

As imagens no infográfico ora analisado ganham diferentes dimensões, passando de um plano bidimensional para tridimensional. Uma figura em três dimensões (3D) ganha profundidade e mais realidade. Podemos citar como exemplos de profundidade nesse infográfico as seguintes imagens: edifício, casa, vaso sanitário, caixa d’água, entre outras. 
A análise da segunda categoria nos apresenta que, para 73,3\% (setenta e três vírgula três por cento) dos alunos entrevistados, a distribuição das informações é o aspecto que mais chama a atenção na leitura multimodal do infográfico, atingindo o segundo maior percentual.

Para ilustrar essa situação, fizemos a seleção das respostas de três participantes da investigação e transcrevemos a seguir:

"O que mais me chamou a atenção foram os desenhos e a distribuição dos dados trazidos pelo infográfico" (A3).

"A distribuição dos dados e informações, pois podem vir de maneira diferente e contribui para um melhor aprendizado" (A6).

"A distribuição das informações e dados de um jeito dinâmico" (A8).

O modo como as informações são organizadas no infográfico atraem o olhar do leitor. Em nossa análise, constatamos que a distribuição dos dados e informações ocupa um espaço considerável no infográfico ora analisado, abrangendo título, subtítulo, captação da água, uso e reaproveitamento. O título "Prevenir a seca" está no alto, na margem, situa-se à esquerda por se tratar de uma informação dada e é saliente para atrair a atenção do leitor (KRESS; VAN LEEUWEN, 2006[1996]). No nosso entendimento, traz uma certa ambiguidade ao passar a ideia de prevenção da seca, o fenômeno climático que assola ciclicamente a região Nordeste e esporadicamente outras regiões do Brasil. No entanto, o subtítulo do infográfico, que aparece ao lado do título, desfaz essa possível ambiguidade, ao informar que "o uso indiscriminado da água está esgotando rapidamente as reservas globais desse recurso vital" (SUPERINTERESSANTE, 2013) e é menos saliente do que o título por estar escrito em letra menor.

A análise da terceira categoria nos exprime que, para 46,7\% (quarenta e seis vírgula sete por cento) dos entrevistados, o aspecto que mais chama a atenção na leitura multimodal do infográfico são as cores, resultando no terceiro percentual entre os itens analisados.

Fizemos a seleção de duas respostas que ilustram a escolha das cores como um componente que desperta o interesse dos alunos e transcrevemos a seguir:

"Os desenhos, os gráficos e as cores, pois são eles que me chamam mais atenção” (A13).

"As ilustrações, cores usadas, a maneira como as informações são distribuídas no espaço” (A15).

No infográfico analisado, as cores são marcadores de modalidade da escala de diferenciação (KRESS; VAN LEEUWEN, 2006[1996]), com predominância do azul (que remete à água) e do branco (que contrasta e suaviza) para expressar a cristalinidade da água usada racionalmente. Também há a presença do vermelho na cobertura da casa, estação de tratamento, caminhão e caixa d'água para irrigação, e do verde suave nas plantações do setor de agricultura. Para Vieira (2015), o contraste entre as cores atrai a atenção do leitor. 
A análise da quarta categoria nos expressa que, para 33,4\% (trinta e três vírgula quatro por cento) dos alunos entrevistados, os gráficos são o elemento que mais chamam a atenção na leitura multimodal do infográfico, ficando com o menor percentual.

Em nosso entendimento, os gráficos chamaram a atenção dos alunos em percentual menor do que outros componentes porque em sua constituição são contemplados elementos que já integram outros aspectos citados, caracterizando-se simultaneamente como uma imagem que tem cor e apresenta dados.

A seguir, citamos uma resposta que aponta os gráficos como um elemento que mais chama a atenção dos alunos na leitura multimodal do infográfico, em que o aluno Ar inclui também as imagens em sua afirmativa: "As imagens e os gráficos" (A1).

No infográfico analisado há apenas um gráfico, sob a forma de pizza, mostrando o percentual do consumo de água por cada setor de atividade: agricultura $-70 \%$; indústria $20 \%$; e uso doméstico - $10 \%$, informando que o setor agrícola é o maior consumidor de água.

Os dados obtidos nas respostas dos alunos estão de acordo com o posicionamento de Braga (2009), ao observar que o infográfico possui a característica de chamar a atenção do leitor e de atraí-lo por meio de imagens e outros elementos visuais.

As respostas dos alunos à pergunta que formulamos sobre os aspectos que mais thes chamam a atenção na leitura do infográfico confirmam as argumentações de Coscarelli (2002) e Lima (2015), pois, os participantes da pesquisa não seguem uma estrutura rígida ou determinada, fazendo a escolha entre as partes do infográfico que mais lhes atraem.

A segunda pergunta dirigida aos participantes da pesquisa voltou-se mais especificamente para os procedimentos de leitura adotados pelos alunos: Que estratégias cognitivas você usou na leitura multimodal do infográfico? A exemplo do questionamento anterior, essa pergunta também permitia que o aluno informasse mais de uma estratégia adotada na leitura do infográfico. Dessa forma, cada estratégia adotada pode atingir o seu percentual de até cem por cento, e a soma de todas as estratégias utilizadas consequentemente pode ser superior a cem por cento. Mostramos o resultado das repostas dos alunos no Gráfico 2. 
Gráfico 2 - Estratégias cognitivas de leitura multimodal do infográfico adotadas pelos alunos

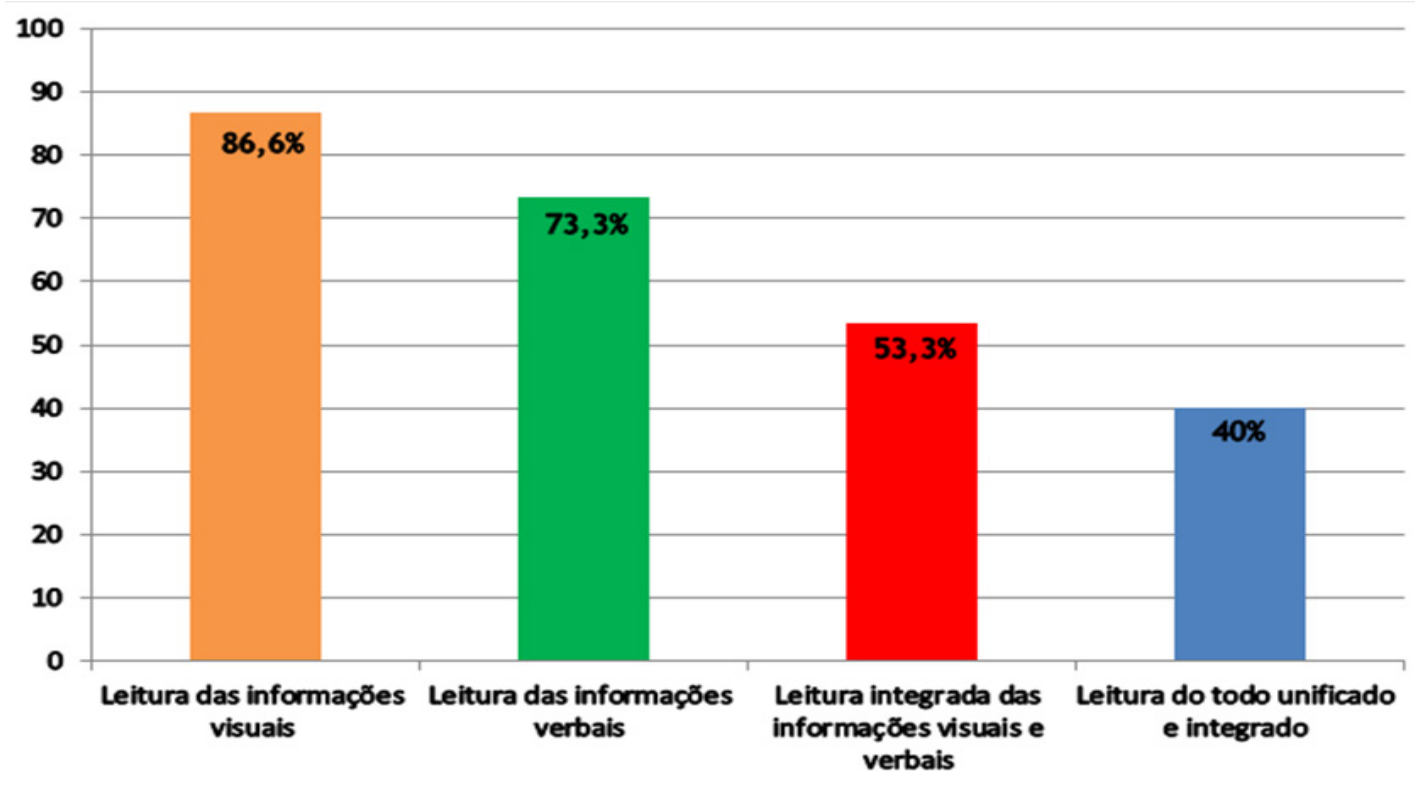

Fonte: Elaboração própria

As respostas dos alunos foram analisadas em quatro estratégias do esquema adotado por Paes de Barros (2009): leitura das informações visuais (86,6\%), leitura das informações verbais $(73,3 \%)$, leitura integrada das informações visuais e verbais $(53,3 \%)$ e leitura do todo unificado e integrado (40\%).

A análise da primeira estratégia cognitiva adotada pelos alunos na leitura do infográfico nos revela que $86,6 \%$ (oitenta e seis vírgula seis por cento) dos entrevistados fizeram a leitura das informações visuais, abrangendo imagens sobre a captação, uso e reaproveitamento da água em três setores: agricultura, indústria e doméstico, constituindo o percentual mais elevado de respostas dos participantes da investigação.

Chamamos a atenção para o fato de que o resultado obtido nessa estratégia cognitiva de leitura das informações visuais $(86,6 \%)$ guarda consonância com o resultado alcançado na pergunta anterior de que as imagens constituem o aspecto que mais chama a atenção dos alunos na leitura do infográfico (80\%).

Podemos ilustrar a constatação de que os alunos realizaram primeiramente a leitura das informações visuais do infográfico, com as respostas de dois alunos selecionadas no roteiro de entrevista estruturada:

"Pelas imagens, para ter uma noção de que assunto estava tratando os textos" (A5). 
"Primeiro observei as imagens, logo após li o título, e as informações contidas nos cantos, li aleatoriamente" (A9).

Notamos que os dois alunos responderam que iniciaram a leitura pelas imagens do infográfico, antes mesmo da leitura do título. $O$ aluno $A 5$ explica que começou pela leitura das imagens para ter uma ideia de qual tema o infográfico estava tratando. Por sua vez, o aluno A9 não justifica o motivo, mas assume que iniciou pela observação das imagens.

Esse tipo de estratégia de leitura organiza as informações da sintaxe visual mediante a observação dos elementos imagéticos, de modo a selecionar as informações relevantes à construção da significação (PAES DE BARROS, 2009) a respeito da ideia de prevenir a seca com o uso racional da água.

A análise da segunda estratégia cognitiva utilizada pelos alunos na leitura do infográfico nos mostra que 73,3 \% (setenta e três vírgula três por cento) dos entrevistados efetuaram a leitura das informações verbais, tais como: título do infográfico, subtítulo, dados de consumo da água por setor e informações sobre captação, uso racional e reaproveitamento da água, ficando em segunda posição no que diz respeito ao percentual das respostas dos colaboradores da pesquisa.

A seguir, ilustramos a análise da estratégia cognitiva de leitura das informações verbais com as respostas de dois alunos participantes da experiência:

"Comecei pelo título e fiz uma relação entre as partes não verbais, aleatoriamente" (A4).

"Primeiro li o título, depois as imagens, seguindo a ordem da esquerda para direita, de cima para baixo" (A7).

Observamos que ambos os alunos afirmaram que começaram a leitura do infográfico pelo título: "Prevenir a seca", que é uma informação do modo verbal. Depois leram as imagens, que fazem parte do modo visual.

A seleção e a verificação das informações verbais estão de acordo com a visão de Paes de Barros (2009, p.166), consistindo em uma estratégia cognitiva que se refere "à ativação das capacidades de compreensão e apreciação da leitura dos textos verbais, como parte do processo de compreender a significação do texto como um todo".

A análise da terceira estratégia cognitiva adotada pelos alunos na leitura do infográfico nos revela que 53,3\% (cinquenta e três vírgula três por cento) dos entrevistados efetuaram a leitura integrada das informações visuais e verbais, alcançando o terceiro percentual de respostas.

Como vemos, essa estratégia cognitiva envolve a integração das informações visuais e verbais na leitura do infográfico. Selecionamos as respostas de dois alunos no roteiro de entrevista estruturada para ilustrar essa estratégia de leitura: 
"Li as imagens primeiramente, depois os textos verbais e os demais elementos não verbais” (A8).

"Primeiro o título, depois as imagens, depois os gráficos e informações destacadas e por último o texto verbal, por curiosidade sobre o tema" (A10).

Nas duas respostas dos alunos, verificamos que há uma sequência na leitura caracterizada pelo uso de marcadores. O aluno A8 emprega as expressões "primeiramente" e "depois". Por sua vez, o aluno Aro faz uso de "primeiro", "depois" (duas vezes) e "por último". Em ambas as situações, o emprego desses marcadores indica a ordem de escolha de elementos verbais e visuais na leitura do infográfico. No entanto, independente da ordem de escolha, o importante nessa estratégia é a integração entre o verbal e o visual para compreensão do infográfico.

Essa estratégia de leitura é considerada mais complexa do que as duas anteriores porque leva em conta a integração das informações verbais e visuais. Paes de Barros (2009) observa que essa estratégia cognitiva exige do leitor a capacidade de observar e conjugar as informações verbais e visuais de forma relacionada para se obter a construção de sentidos na leitura do infográfico.

Paiva (2016, p. 49) considera essa estratégia como sendo uma habilidade complexa de leitura do infográfico em que o leitor precisa relacionar "diferentes modos de apresentação como o verbal e o visual, por exemplo", havendo a necessidade de "avaliar se as articulações estabelecidas são corretas, pertinentes e adequadas a seu propósito”.

A análise da quarta estratégia cognitiva usada pelos alunos na leitura do infográfico nos permite constatar que $40 \%$ (quarenta por cento) dos entrevistados procederam à leitura do todo unificado e integrado, atingindo o menor percentual de respostas por se tratar de procedimento de leitura mais complexo do que os demais anteriormente analisados. Apresentamos a seguir as respostas de dois alunos para ilustrar essa estratégia cognitiva de leitura:

"Eu li primeiro o título, depois visualizei as imagens principais e depois fui ligando as demais informações, ou seja, li de forma bem aleatória" (A1).

"Eu li de forma aleatória, iniciei pelos textos não verbais, imagens, gráficos, etc., e em seguida fui lendo os textos verbais de forma relacionada" (A6).

Notamos que esses dois alunos realizam uma leitura do todo, de maneira integrada, abrangendo aspectos verbais e de outros modos da linguagem do infográfico. O aluno Ai informa como fez essa integração, marcada pelo uso do termo "ligando": "[...] depois fui ligando as demais informações [...]". E o aluno A6 afirma como realizou uma leitura integrada, caracterizada pela expressão de "forma relacionada": "[...] e em seguida fui lendo os textos verbais de forma relacionada”. Esclarecemos que a palavra "aleatória” que aparece em ambas 
as respostas selecionadas, nesse contexto em que é usada, não significa falta de integração, serve para mostrar que a leitura não foi linear, ou seja, não obedeceu a uma ordem sequencial.

Essa constatação está de acordo com a proposta de Paes de Barros (2009) de que nessa estratégia cognitiva de leitura há uma percepção do todo unificado e integrado, abrangendo a integração de todos os modos semióticos, mediante a ativação das capacidades linguístico-discursivas e de leitura associadas à organização/observação das informações, por meio das quais o leitor constrói um todo significativo para compreensão do infográfico.

Seguindo essa linha de pensamento, Roza e Menezes (2019, p. 132) argumentam que "a leitura do texto multimodal requer o desenvolvimento das capacidades com diferentes semioses em seu conjunto, de modo integrativo e interativo". As autoras ainda acrescentam que a falta de percepção de um dos componentes das semioses que constituem o texto multimodal implicará na incompletude de sua compreensão leitora.

Conforme mostramos na análise referente à primeira pergunta do roteiro de entrevista estruturada, embora os leitores tenham preferência pela leitura do que lhes chama mais atenção, a falta de percepção de elementos de um determinado modo semiótico ou dos diferentes modos como um todo unificado e integrado prejudica a compreensão e afeta a potencialização dos sentidos do infográfico.

\section{Considerações finais}

Esta pesquisa teve como foco principal um estudo de leitura multimodal do gênero textual infográfico, realizada por meio de etapas metodológicas que se revelaram eficientes, em aulas de língua portuguesa com alunos do $3^{\circ}$ ano do ensino médio de uma escola pública da rede estadual da educação básica.

Para o estudo de leitura multimodal em sala de aula, selecionamos um infográfico com o título de "Prevenir a seca", publicado pela revista Superinteressante (2013), com um tema de interesse social, mostrando informações sobre o risco do esgotamento das reservas de água e orientações sobre o uso racional desse recurso vital para a vida no planeta.

De início, verificamos, por meio de diagnóstico, que 80,8\% (oitenta vírgula oito por cento) dos alunos participantes da experiência conheciam infográficos por meio de revistas, jornais, livro didático, redes sociais, televisão, propagandas, simulados e provas, ao passo que 19,2\% (dezenove vírgula dois por cento) não conheciam esse gênero textual. Observamos que mesmo os alunos que já tinham conhecimento do infográfico não haviam participado de um estudo dessa natureza em sala de aula de língua portuguesa no ensino médio.

Procedemos à análise da experiência em aula de língua portuguesa tomando duas questões como parâmetros: o que chama mais a atenção dos alunos e as estratégias cognitivas utilizadas pelos alunos na leitura multimodal do infográfico. 
Os aspectos que mais chamaram a atenção dos alunos na leitura multimodal do infográfico foram: as imagens (80\%), a distribuição das informações $(73,3 \%)$, as cores $(46,7 \%)$ e os gráficos $(33,4 \%)$.

As estratégias cognitivas de leitura multimodal do infográfico utilizadas pelos alunos, com base no esquema proposto por Paes de Barros (2009), foram: leitura das informações visuais $(86,6 \%)$, leitura das informações verbais $(73,3 \%)$, leitura integrada das informações verbais e visuais $(53,3 \%)$ e leitura do todo unificado e integrado (40\%).

De acordo com a análise dos resultados da experiência, constatamos que, para explorar adequadamente a leitura do infográfico em aula de língua portuguesa e contribuir para a produção de sentidos, precisamos articular os componentes multimodais, notadamente pela integração dos modos semióticos visual e verbal.

Concluímos que, embora as imagens chamem mais a atenção dos alunos e que estes tenham utilizado em maior percentual a estratégia cognitiva de leitura das informações visuais, a falta de percepção de componentes de um determinado modo semiótico ou dos diferentes modos como um todo unificado e integrado prejudica a leitura multimodal do infográfico e afeta a compreensão e a produção de sentidos.

Essa conclusão nos leva a refletir que o infográfico é um gênero multimodal que se enquadra no contexto das mudanças comunicacionais que a sociedade pós-moderna vem passando, podendo contribuir para tornar as aulas de língua portuguesa no ensino médio mais dinâmicas e atrativas.

Por fim, esperamos que este estudo possa contribuir para uma reflexão sobre as aulas de língua portuguesa, bem como despertar o interesse para realização de pesquisas futuras sobre diferentes aspectos da leitura multimodal do infográfico aplicados ao contexto escolar do ensino médio.

\section{REFERÊNCIAS}

AQUINO, Lucélio Dantas de. A escrita midiática à luz da multimodalidade discursiva: os memes da internet. In: MARTINS, M. A.; SÁ JÚNIOR, L. A.; CAMPOS, S. F. (orgs.). JORNADA NACIONAL DO GELNE, 25., Anais [...] Natal: EDUFRN, 2014. p. 1336-1337. Disponível em: http://www.gelne.com.br/arquivos/anais/gelne-2014/ anexos /1112.pdf. Acesso em: 20 set. 2019.

BRAGA, Carla Souza. O infográfico na educação a distância: uma contribuição para a aprendizagem. In: $\mathbf{1 5}^{\circ}$ Congresso Internacional ABED de Educação a Distância. Fortaleza, 2009.Disponível em:http://www.abed.org.br/congress02009/cd/trabalhos/1352009201831. pdf. Acesso em: 8 nov. 2019.

BRASIL. Ministério da Educação. Base Nacional Comum Curricular: educação é a base. [Versão final]. Brasília: MEC/CONSED/UNDIME, 2018. 
COSCARELLI, Carla Viana. Entre textos e hipertextos. In: COSCARELLI, Carla Viana (org.). Novas tecnologias, novos textos, novas formas de pensar. Belo Horizonte: Autêntica, 2002. p. 65-84.

DIONÍSIO, Angela Paiva. Gêneros textuais e multimodalidade. In: KARWOSKI, A. M.; GAYDECZKA, B.; BRITO, K. S. (orgs.). Gêneros textuais: reflexões e ensino. São Paulo: Parábola, 2011. p. 137-152.

DIONISIO, Angela Paiva; VASCONCELOS, Leila Janot de. Multimodalidade, gênero textual e leitura. In: BUNZEN, Clecio; MENDONÇA, Márcia (orgs.). Múltiplas linguagens para o ensino médio. São Paulo: Parábola, 2013. p. 19-42 (Estratégias de Ensino, 38).

DIONISIO, Angela Paiva; VASCONCELOS, Leila Janot de; SOUZA, Maria Medianeira de (Orgs.). Multimodalidades e leituras: funcionamento cognitivo, recursos semióticos, convenções visuais. Recife: Pipa Comunicação, 2014. (Série experimentando teorias em linguagens diversas, v.1).

FERRAZ, Janaína de Aquino. Gêneros multimodais: novos caminhos discursivos. ENCONTRO NACIONAL DE LINGUAGEM VERBAL E NÃO VERBAL, 8., São Paulo, 2008. In: ESTUDOS DO DISCURSO: DIFERENTES PERSPECTIVAS, Anais [...], p. 1-14, 2008. Disponível em: http:// www.fflch.usp.br/dlcv/enil/pdf/2_Janaina_AF.pdf. Acesso em: 2 out. 2019.

FURST, Mariana Samos Bicalho Costa. Infográficos: habilidade na leitura do gênero por alunos do ensino médio e ensino superior. 2010. 207 f. Dissertação (Mestrado em Estudos Linguísticos) - Faculdade de Letras, Programa de Pós-Graduação em Estudos Linguísticos, Universidade Federal de Minas Gerais, Belo Horizonte, 2010.

KRESS, Gunther; VAN LEEUWEN, Theo. Multimodal discourse: the modes and media of contemporary communication. London: Arnold, 2001.

KRESS, Gunther; VAN LEEUWEN, Theo. Reading images: the grammar of visual design. 2nd ed. London and New York: Routledge, 2006[1996]).

LIMA, Ricardo Cunha. O que é infografia jornalística? InfoDesign: Revista Brasileira de Design da Informação/Brazilian Journal of Information Design, São Paulo, v. 12, n. 1, 2015, p.111-127. Disponível em: https://www.infodesign.org.br/infodesign/article/view/312/219. Acesso em: 30 out. 2019.

NEVES, José Luís. Pesquisa qualitativa - características, usos e possibilidades. Caderno de Pesquisas em Administração, São Paulo, v. 1, n. 3, 2º sem./1996, p. 1-5. 
OLIVEIRA, Tamara Lyz Milhomem de. "Entendeu ou quer que eu desenhe?" O gênero infográfico no ensino de língua portuguesa. In: SIELP - SIMPÓSIO INTERNACIONAL DE ENSINO DE LÍNGUA PORTUGUESA, 6., v. 4, n. 1. 2016. Instituto de Letras e Linguística. Anais [...], p. 773-787. Uberlândia, MG: EDUFU, 2017. Disponível em: https://www.recantodasletras. com.br/artigos-de-ciencia-e-tecnologia/6308708. Acesso em: 26 set. 2019.

PAES DE BARROS, Cláudia Graziano. Capacidades de leitura de textos multimodais. Polifonia, Cuiabá, Edufmt, n. 19, p. 161-186, 2009.

PAIVA, Francis Arthuso. Leitura de imagens em infográficos. In: COSCARELLI, Carla Viana (org.). Tecnologias para aprender. São Paulo: Parábola, 2016. (Linguagens e Tecnologias; 3).

ROZA, Edleide Santos; MENEZES, Ângela Maria de Araújo. Multimodalidade: aplicação e ressignificação dos sentidos - novas conexões em ambiente escolar. In: AZEVEDO, Isabel Cristina Michelan de; COSTA, Renata Ferreira (orgs.). Multimodalidade e práticas de multiletramentos no ensino de línguas. São Paulo: Blucher, 2019. p. 123-145. [Cap. 6].

SUPERINTERESSANTE. Prevenir a seca [Infográfico]. São Paulo, Abril, edição 322, ago. 2013. Disponível em: http://planetasustentavel.abril.com.br/pops/prevenir-a-seca-infograficosuper-agosto.shtml. Acesso em: 15 dez. 2019.

THIOLLENT, Michel. Metodologia da pesquisa-ação. 14. ed. São Paulo: Cortez, 2005. (Coleção temas básicos de pesquisa-ação).

VIEIRA, Josenia. Multimodalidade nos eventos de letramento. In: VIEIRA, Josenia; SILVESTRE, Carminda.[coautoras]. Introdução à multimodalidade: contribuições da gramática sistêmicofuncional, análise de discurso crítica, semiótica social. - Brasília, DF: J. Antunes Vieira, 2015. p. 43-72.

Recebido para publicação em: 5 out. 2020. Aceito para publicação em: 11 jan. 2021. 